\title{
Reproducing Multi-Carrier Modulation Schemes for Visible Light Communication with the Ripple Modulation Technique
}

\author{
Juan Rodríguez, Member, IEEE, Diego G. Lamar, Member, IEEE, Daniel G. Aller, Student \\ Member, IEEE, Pablo F. Miaja, Member, IEEE, and Javier Sebastián, Senior Member, IEEE.
}

\begin{abstract}
The Ripple Modulation (RM) is a technique that provides a variable output voltage by using the output voltage ripple of a Switching-Mode Power Converter (SMPC). It was proposed to reproduce the communication signal of a Visible Light Communication (VLC) transmitter, thus avoiding the use of power inefficient Linear Power Amplifiers (LPAs). However, the RM has a major drawback: it has not been reported how to reproduce Multi-Carrier Modulation (MCM) schemes, which are the preferred modulation schemes due to their high performance in wireless communications. In this work, it is demonstrated that the RM can be used to reproduce MCM schemes by considering the envelope and the instantaneous phase of the communication signal. Moreover, the control system of the power stage is described in detailed, explaining how to modulate both the width and the phase of the gate signals, the calculation of the phase-shift that is required for tracking the envelope, etc.
\end{abstract}

Index Terms- Visible Light Communication (VLC), High-Brightness LED (HB-LED), Ripple Modulation (RM), Multi-Carrier Modulation (MCM), high efficiency.

\section{INTRODUCTION}

$\mathrm{N}_{\mathrm{i}}^{\mathrm{o}}$ OWADAYS, the use of wireless communication systems is essential for the present and future society. The mobile data traffic has grown exponentially during last decade and it is expected that it will keep growing at similar rates at least until 2021 [1]. Moreover, emerging topics, such as the Internet of Things (IoT) or the smart cities, show that the current trend is to interconnect wirelessly humans and different kinds of items placed in the environment (clothes, cars, city lighting, home appliances, etc.) [2], [3]. As a result, the Radio Frequency (RF) spectrum is already close to congestion and, therefore, enabling

Manuscript received October 30, 2018; revised January 29, 2019 and March 13, 2019; accepted March 27, 2019. This work was supported by the Spanish Government under the Project MINECO-17-DPI201675760-R, the scholarship FPU14/03268, the Principality of Asturias under the Project IDI/2018/000179, the grant BP17-91 and by European Regional Development Fund (ERDF).

J. Rodríguez, D. G. Lamar, D. G. Aller, P. F. Miaja, and J. Sebastian are with the Departamento de Ingeniería Eléctrica, Electrónica, de Computadores y Sistemas, Universidad de Oviedo, Gijón 33204, Spain (e-mail: \{rodriguezmjuan, gonzalezdiego, garciaadaniel, fernandezmiapablo, sebas\}@uniovi.es). the data traffic predicted for upcoming years needs for further research on new technologies. Looking at higher and unexplored frequency bands and using the light as the transmission medium is the logical step to alleviate the problem. Visible Light Communication (VLC) is an optical wireless communication subset that has caught the attention of many communication researchers [4]-[7]. This wireless communication system uses the wide and unlicensed visible light spectrum (430-750 THz) to transmit information. The strength of this approach arises when the communication is combined with the lighting functionality of High-Brightness Light-Emitting Diodes (HB-LEDs). Differently from other lighting devices, HB-LEDs have the capability to perform fast light changes, which enables the communication. In VLC, the information transmission is performed by modulating the light intensity waveform emitted by the HB LEDs $(s(t))$. After that, $\mathrm{s}(\mathrm{t})$ is demodulated in the receiver by using a photodetector. This technique, where the optical power is modulated to transmit the information, is referred as Intensity Modulation/Direct Detection (IM/DD) [8]. In order to fulfill both the lighting and the communication tasks, $\mathrm{s}(\mathrm{t})$ is made up of a DC component $\left(\mathrm{s}_{\mathrm{DC}}\right)$ that establishes the lighting level and a high frequency $\mathrm{AC}$ component $\left(\mathrm{s}_{\mathrm{AC}}(\mathrm{t})\right)$ that cannot be seen by a human eye and that is determined by the modulation scheme:

$$
s(t)=s_{D C}+s_{A C}(t)
$$

The design of the HB-LED driver for performing VLC is a very challenging task [9]. Depending on the HB-LED kind, its bandwidth ranges between 3 and $20 \mathrm{MHz}$ [10]. The HB-LED driver must be able to make use of all the bandwidth provided by the light source in order to maximize the bit rate. In other words, the HB-LED driver should not be the element that limits the communication speed. Moreover, the bit rate depends not only on the bandwidth, but also on the modulation scheme that is used to transmit the information. In this sense, being able to reproduce Multi-Carrier Modulation (MCM) schemes (i.e., the preferred modulation scheme for wireless communication systems) is an important challenge. Those modulation schemes are very efficient from the communication perspective, which leads to a high ratio between bit rate and demanded bandwidth. 
In addition, they are robust against the multipath fading. This phenomenon is caused by the different propagation paths of the signal, which is translated into different time delays of the light beams that reach the receiver, increasing the error during the demodulation process. These features lead to the wide use of MCM schemes in wireless communication systems, such as Wifi [11], and explain why they are the preferred modulation schemes for VLC [4], [12]-[14].

Typically, the HB-LED driver used for reproducing MCM schemes is made up of a Switching-Mode Power Converter (SMPC) that is responsible for biasing the HB-LEDs, and a Linear Power Amplifier (LPA) that delivers the AC component [9]. The bandwidth of the LPA is high enough for reproducing the fast current waveforms that are needed. However, its power efficiency is very low, which damages the high power efficiency of HB-LED lighting. Take into account that a Class A or AB LPA offers very low power efficiency (between 10\% and $40 \%$ depending on the MCM scheme). Another option is to use a SMPC based on the Pulse Width Modulation (PWM) technique (PWM-SMPC) to perform both the lighting and the communication tasks to increase the power efficiency [15], [16]. Buck-derived converters can be used to reduce the high switching frequency $\left(f_{S}\right)$ that is required for enabling the communication bandwidth. However, it is done at the expense of increasing the complexity of the power stage (i.e., higher number of SMPCs, switches, input voltages, etc.).

Recently, it has been demonstrated that the output voltage ripple of a two-phase synchronous buck converter can be used to reproduce communication signals [17]. This technique, which will be noted as Ripple Modulation (RM), is very promising because it achieves high efficiency, the power stage is quite simple and the required $\mathrm{f}_{\mathrm{S}}$ is much lower than in the case of PWM-SMPCs. As an example, the modulation schemes reproduced in [15] and [17] are very similar (the modulation scheme reproduced in [17] is a little more sophisticated). In the case of [15], the modulation scheme is reproduced by means of a PWM-SMPC whose $\mathrm{f}_{\mathrm{S}}$ is $4.5 \mathrm{MHz}$. In [17] the modulation scheme is reproduced with a SMPC based on the RM and, consequently, $\mathrm{f}_{\mathrm{S}}$ is much lower: $500 \mathrm{kHz}$. The drawback of the $\mathrm{RM}$ is that, in principle, it is not able to reproduce MCM schemes. The present work aims to improve the RM by presenting a theoretical method for reproducing MCM schemes and by describing the power stage control system used to implement that method [18].

The paper is organized as follows. The RM is reviewed in Section II. Section III is focused on explaining a method for reproducing MCM schemes by means of the RM. The power stage control system is described in Section IV. Section V studies the experimental prototype. Finally, the conclusions are gathered in Section VI.

\section{ReVIeW of The RM}

The RM was proposed for reproducing Single-Carrier Modulation (SCM) schemes [17], where the information is transmitted by the amplitude or/and the phase changes of a cosine waveform (i.e., the carrier). Hence, the voltage that the HB-LED driver provides can be expressed in this way:

$$
\begin{gathered}
v_{O}(t)=v_{O-D C}+v_{O-A C}(t), \\
v_{O-A C}(t)=A_{V}(t) \cos \left(2 \pi f_{S} t+\phi_{V}(t)\right),
\end{gathered}
$$

where $\mathrm{V}_{\mathrm{O}-\mathrm{DC}}, \mathrm{V}_{\mathrm{O}-\mathrm{AC}}(\mathrm{t}), \mathrm{Av}_{\mathrm{v}}(\mathrm{t})$ and $\phi_{\mathrm{v}}(\mathrm{t})$ are the $\mathrm{DC}$ component, the AC component, the amplitude and the phase modulation of the voltage, respectively. The method to control $v_{O-D C}, A_{V}(t)$

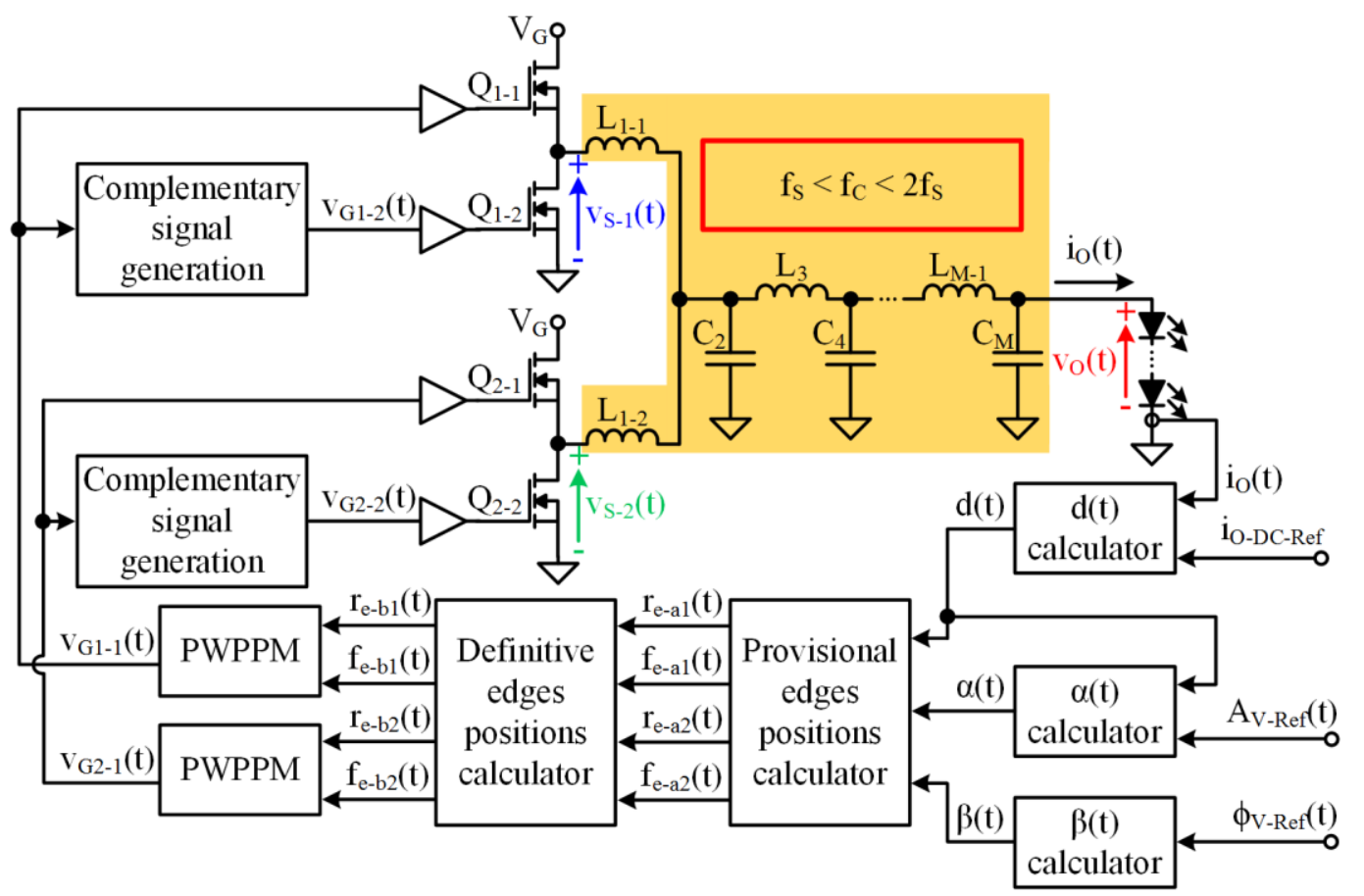

Fig. 1. Power stage and blocks diagram of the control system used to apply the RM. 
and $\phi_{\mathrm{v}}(\mathrm{t})$ by using the output voltage ripple of a SMPC will be review below. The proposed SMPC topology is a two-phase synchronous buck converter with high order output filter (see Fig. 1). Since the communication signal is reproduced by means of the output voltage ripple, the output filter design differs from the conventional one of a PWM-SMPC. In this case the filter passes not only the DC component of both switch-node voltages $\left(v_{S-1}(t)\right.$ and $\left.v_{S-2}(t)\right)$, but also their $1^{\text {st }}$ switching harmonic. Hence, the cut-off frequency of the low-pass filter $\left(\mathrm{f}_{\mathrm{C}}\right)$ must be between $\mathrm{f}_{\mathrm{S}}$ and $2 \cdot \mathrm{f}_{\mathrm{S}}$. Moreover, the SMPC is not controlled by applying the PWM. It is controlled by using a more complex technique that is noted as Pulse-Width and Pulse-Phase Modulation (PWPPM) in this paper. As Fig. 2 shows, it implies that not only the pulses width is controlled, but also their position over the switching period $\left(\mathrm{T}_{\mathrm{S}}\right)$. The duty cycle $(\mathrm{d}(\mathrm{t}))$ determines the pulses width. It is important to note that controlling the pulses phase is equivalent to control their position. The dimensionless parameter that is used to control the pulses phase is noted as $\gamma(\mathrm{t})$ (see Fig. 2), and it ranges between 0 and 1. When $\gamma(\mathrm{t})$ is 0 , the pulse phase is 0 radians, and when $\gamma(\mathrm{t})$ is 1 , the pulse phase is $-2 \cdot \pi$ radians. Therefore, the pulse phase is equal to $-2 \cdot \pi \cdot \gamma(\mathrm{t})$ radians and, consequently, the center of the pulse appears $\mathrm{T}_{\mathrm{S}} \cdot \gamma(\mathrm{t})$ after the beginning of the switching period (see Fig. 2). Note that the phase is determined by the pulse center. In the $\mathrm{RM}, \mathrm{d}(\mathrm{t})$ is the same for both phases of the converter while the pulses phases (i.e., the pulses positions) are modulated independently by means of two values of $\gamma(\mathrm{t})$ : $\gamma_{1}(\mathrm{t})$ and $\gamma_{2}(\mathrm{t})$.

The superposition theorem allows us to calculate the relationship between $\mathrm{V}_{\mathrm{O}}(\mathrm{t})$ and the control parameters by analyzing the voltage contribution of each phase of the SMPC:

$$
v_{O}(t)=v_{O-1}(t)+v_{O-2}(t)
$$

where $\mathrm{v}_{\mathrm{O}-1}(\mathrm{t})$ and $\mathrm{v}_{\mathrm{O}-2}(\mathrm{t})$ are the output voltages provided by phases 1 and 2, respectively. The equivalent circuit depicted in Fig. 3 can be obtained by considering that the phase inductors are equal and by applying the Thevenin's theorem. This circuit considers the switch-node voltage (i.e., $\mathrm{v}_{\mathrm{S}-i}(\mathrm{t})$ ) divided by two and applied to a low-pass filter, where the equivalent first inductor $\left(\mathrm{L}_{1}\right)$ is half the phase inductor $\left(\mathrm{L}_{1-i}\right)$. The voltage contribution of each phase can be calculated by taking into account that the filter passes not only the DC component, but also the $1^{\text {st }}$ switching harmonic, the delay introduced by the filter $\left(\mathrm{t}_{\mathrm{Fil}}\right)$ and the Fourier analysis:

$$
\begin{aligned}
& v_{O-1}\left(t+t_{F i l}\right)=\frac{d(t) V_{G}}{2}+ \\
& \frac{V_{G}}{\pi} \sin (\pi d(t)) \cos \left(2 \pi f_{S} t-2 \pi \gamma_{1}(t)\right), \\
& v_{O-2}\left(t+t_{F i l}\right)=\frac{d(t) V_{G}}{2}+ \\
& \frac{V_{G}}{\pi} \sin (\pi d(t)) \cos \left(2 \pi f_{S} t-2 \pi \gamma_{2}(t)\right) .
\end{aligned}
$$

Substituting (5)-(6) into (4) leads to:

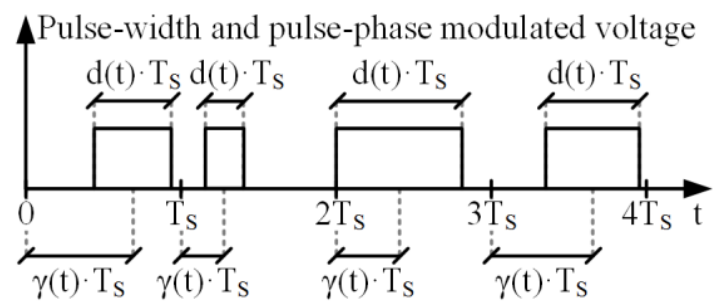

Fig. 2. Pulse-width and pulse-phase modulated voltage.

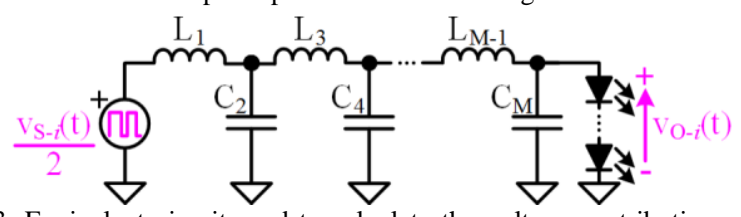

Fig. 3. Equivalent circuit used to calculate the voltage contribution of each phase of the two-phase synchronous buck converter based on the RM.

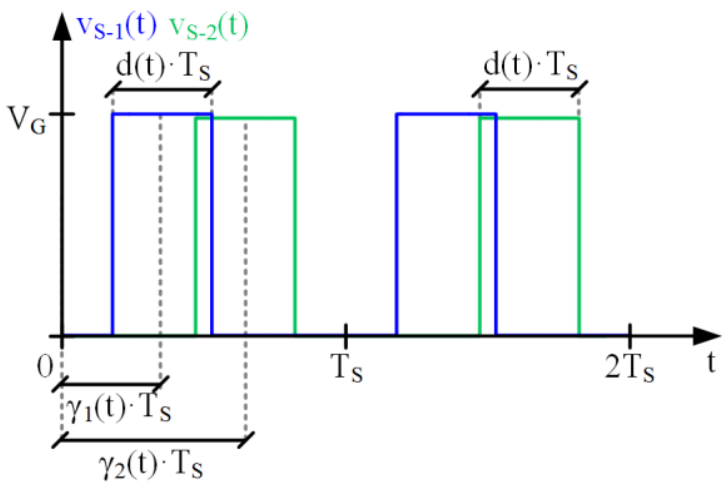

(a)

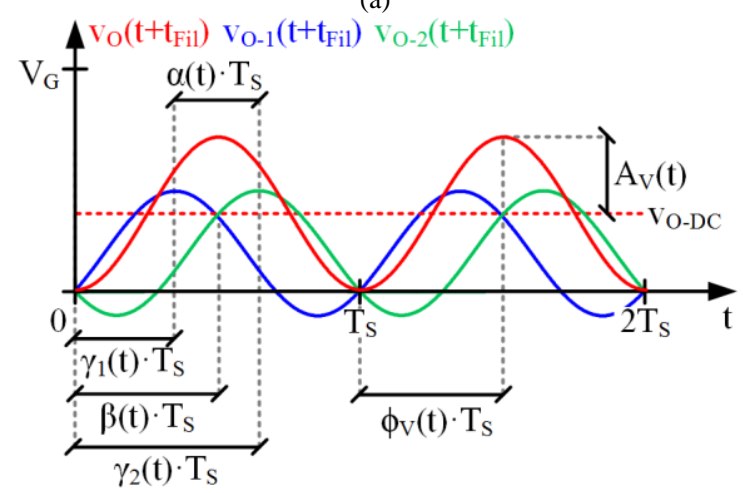

(b)

Fig. 4. Main voltage waveforms of the two-phase synchronous buck converter based on the RM. Note that the output voltage representations cancel $t_{\text {Fil }}$ to facilitate the understanding: (a) Switch-node voltages. (b) Output voltage.

$$
\begin{aligned}
& v_{O}\left(t+t_{F i l}\right)=d(t) V_{G}+ \\
& \frac{2 V_{G}}{\pi} \sin (\pi d(t)) \cos (\pi \alpha(t)) \cos \left(2 \pi f_{S} t-2 \pi \beta(t)\right)
\end{aligned}
$$

where $\alpha(t)$ is the phase-shift between $v_{S-1}(t)$ and $v_{S-2}(t)$ (i.e., the position difference) divided by $2 \cdot \pi$, and $\beta(t)$ is the absolute value of the mean phase of $v_{S-1}(t)$ and $v_{S-2}(t)$ (i.e., the average position) divided by $2 \cdot \pi$ (i.e., the mean value of $\gamma_{1}(\mathrm{t})$ and $\gamma_{2}(\mathrm{t})$ ) [17]. Comparing (2), (3) and (7) allows us to identify $\mathrm{v}_{\mathrm{O}-\mathrm{DC}}$, $\mathrm{A}_{\mathrm{V}}(\mathrm{t})$ and $\phi_{\mathrm{V}}(\mathrm{t})$; and how to control them by means of $\mathrm{d}(\mathrm{t}), \alpha(\mathrm{t})$ and $\beta(t)$, respectively (see Fig. 4):

$$
v_{O-D C}=d(t) V_{G}
$$




$$
\begin{gathered}
A_{V}(t)=\frac{2 V_{G}}{\pi} \sin (\pi d(t)) \cos (\pi \alpha(t)), \\
\phi_{V}(t)=-2 \pi \beta(t) .
\end{gathered}
$$

\section{USING THE RM FOR REPRODUCING MCM SCHEMES}

As was previously explained, being able to reproduce MCM schemes is a very important requirement for VLC. However, it has not been reported how to reproduce those schemes by means of the RM. This point is not trivial because MCM schemes are made up of $N$ cosine waveforms with different frequencies that change their amplitudes and phases over time (see Fig. 5):

$$
\begin{aligned}
& s(t)=s_{D C}+ \\
& \frac{1}{N} \sum_{k=1}^{N} A_{S-M C M-k}(t) \cos \left(2 \pi f_{M C M-k} t+\phi_{S-M C M-k}(t)\right),
\end{aligned}
$$

where $f_{\text {MCM-k }}, A_{S-M C M-k}(t)$ and $\phi_{S-M C M-k}(t)$ are the frequency, the amplitude and the phase modulation of the $k^{\text {th }}$ carrier of $\mathrm{s}(\mathrm{t})$, respectively. Hence, the voltage waveform that is required for reproducing a MCM scheme is:

$$
\begin{aligned}
& v_{O}(t)=v_{O-D C}+ \\
& \frac{1}{N} \sum_{k=1}^{N} A_{V-M C M-k}(t) \cos \left(2 \pi f_{M C M-k} t+\phi_{V-M C M-k}(t)\right)
\end{aligned}
$$

where $A_{V-M C M-k}(t)$ and $\phi_{V-M C M-k}(t)$ are the voltage amplitude modulation and the voltage phase modulation of the $k^{\text {th }}$ carrier, respectively. It is important to note that the dimming level jeopardizes the maximum amplitude of the carriers that can be used [16]. AV-MCM-k $(t)$ and $\phi_{V-M C M-k}(t)$ are obtained from (11):

$$
\begin{aligned}
& A_{V-M C M-k}(t)=\frac{A_{S-M C M-k}(t)}{K_{S-V}}, \\
& \phi_{V-M C M-k}(t)=\phi_{S-M C M-k}(t),
\end{aligned}
$$

where $\mathrm{K}_{\mathrm{S}-\mathrm{v}}$ is the proportionality coefficient between the light intensity of an HB-LED and the voltage across it in the linear region [16].

Since the RM provides only one cosine waveform, a comparison between (7) and (12) does not allow us to identify the references that $A_{v}(t)$ and $\phi_{v}(t)$ must track to reproduce a MCM scheme. Therefore, (12) must be manipulated to reach an expression where only a single cosine waveform changes the amplitude and the phase over time. The first step is to calculate the center frequency of the MCM:

$$
f_{M C M}=\frac{1}{N} \sum_{k=1}^{N} f_{M C M-k} .
$$

After that, the difference between $\mathrm{f}_{\mathrm{MCM}}$ and the frequency of each carrier can be expressed as follows (see Fig. 6):

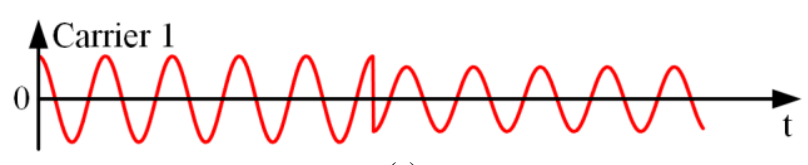

(a)

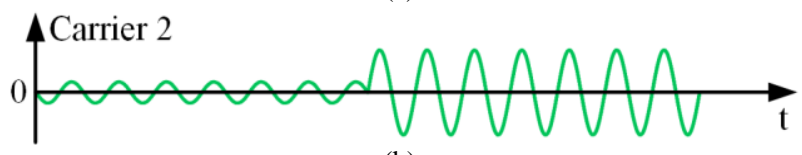

(b)

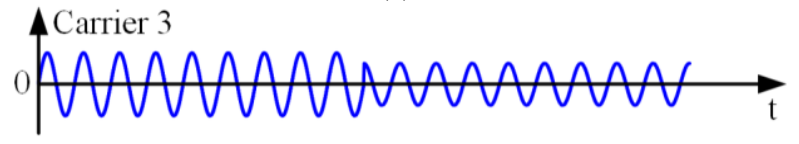

(c)

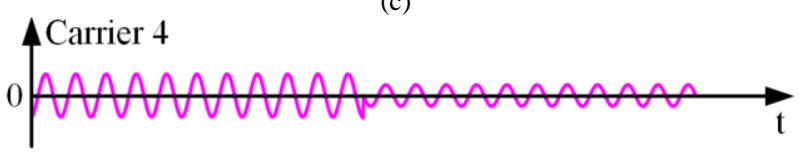

(d)

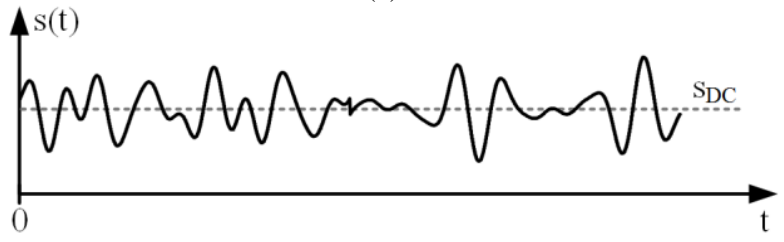

(e)

Fig. 5. Example of a MCM scheme that is made up of 4 carriers: (a) Carrier 1. (b) Carrier 2. (c) Carrier 3. (d) Carrier 4. (e) MCM signal.

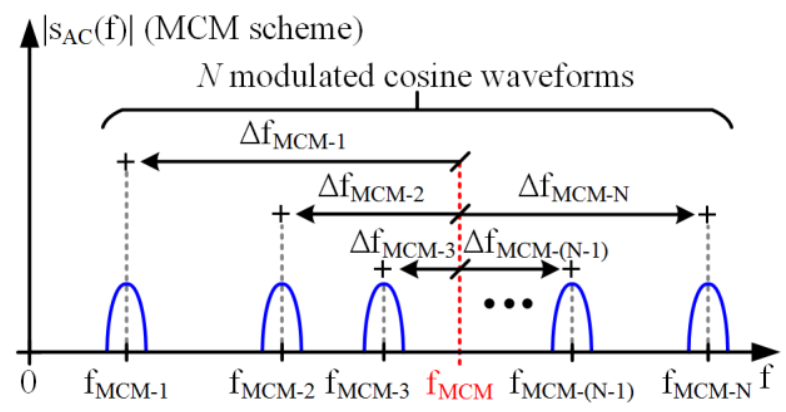

Fig. 6. MCM scheme in the frequency domain.

$$
\Delta f_{M C M-k}=f_{M C M-k}-f_{M C M} .
$$

According to (16), the $k^{\text {th }}$ voltage carrier can be expressed as:

$$
\begin{aligned}
& v_{M C M-k}(t)=A_{V-M C M-k}(t) \cdot \\
& \cos \left(2 \pi\left(f_{M C M}+\Delta f_{M C M-k}\right) t+\phi_{V-M C M-k}(t)\right)= \\
& A_{V-M C M-k}(t) \cos \left(2 \pi f_{M C M} t\right) \cdot \\
& \cos \left(2 \pi \Delta f_{M C M-k} t+\phi_{V-M C M-k}(t)\right)- \\
& A_{V-M C M-k}(t) \sin \left(2 \pi f_{M C M} t\right) \cdot \\
& \sin \left(2 \pi \Delta f_{M C M-k} t+\phi_{V-M C M-k}(t)\right) .
\end{aligned}
$$

Substituting (17) into (12) leads to:

$$
\begin{aligned}
& v_{O}(t)=v_{O-D C}+v_{M C M-I}(t) \cos \left(2 \pi f_{M C M} t\right)- \\
& v_{M C M-Q}(t) \sin \left(2 \pi f_{M C M} t\right),
\end{aligned}
$$

where $\mathrm{V}_{M C M} \mathrm{I}(\mathrm{t})$ and $\mathrm{V}_{M C M} \mathrm{Q}(\mathrm{t})$ are the in-phase and quadrature components of the MCM scheme with respect to a cosine 
waveform whose frequency is $\mathrm{f}_{\mathrm{MCM}}$. These two components are formulated as:

$$
\begin{gathered}
v_{M C M-I}(t)=\frac{1}{N} \sum_{k=1}^{N} A_{V-M C M-k}(t) \\
\cos \left(2 \pi \Delta f_{M C M-k} t+\phi_{V-M C M-k}(t)\right) \\
v_{M C M-Q}(t)=\frac{1}{N} \sum_{k=1}^{N} A_{V-M C M-k}(t) \\
\sin \left(2 \pi \Delta f_{M C M-k} t+\phi_{V-M C M-k}(t)\right) .
\end{gathered}
$$

Finally, the MCM signal can be expressed as a function of a single cosine waveform that changes the amplitude and the phase over time:

$$
\begin{gathered}
v_{O}(t)=v_{O-D C}+ \\
A_{V-M C M}(t) \cos \left(2 \pi f_{M C M} t+\phi_{V-M C M}(t)\right), \\
A_{V-M C M}(t)=\sqrt{v_{M C M-I}(t)^{2}+v_{M C M-Q}(t)^{2}}, \\
\phi_{V-M C M}(t)=\tan ^{-1}\left(\frac{v_{M C M-Q}(t)}{v_{M C M-I}(t)}\right) .
\end{gathered}
$$

Comparing (7) to (21)-(23) allows us to identify both the amplitude modulation and the phase modulation that must be tracked to reproduce MCM schemes. Considering (9)-(10), the control parameters should be modulated as follows:

$$
\begin{gathered}
\alpha(t)=\frac{1}{\pi} \cos ^{-1}\left(\frac{\pi A_{V-M C M}(t)}{2 V_{G} \sin (\pi d(t))}\right), \\
\beta(t)=\frac{-\phi_{V-M C M}(t)}{2 \pi} .
\end{gathered}
$$

It is important to note that $\mathrm{AV}_{\mathrm{V}-\mathrm{MCM}}(\mathrm{t})$ and $\phi_{\mathrm{V}-\mathrm{MCM}}(\mathrm{t})$ are the envelope and the instantaneous phase of the pass-band signal considering a cosine waveform with frequency equal to $\mathrm{f}_{\mathrm{MCM}}$ as the carrier (see Fig. 7). The process described from (17) to (20) is analogous to the low-pass equivalent of a band-pass signal [19]. In fact, the process described in (22) and (23) is the polar representation of the I-Q components of the MCM scheme. Moreover, the method can be used to reproduce any band-pass communication signal. Note that any signal can be used in (22) and (23) instead of the I-Q components of a MCM scheme. In this way, a carrier at the switching frequency of the converter (i.e., $\mathrm{f}_{\mathrm{S}}$ ) would be modulated by an arbitrary waveform defined by the arbitrary signals used in (22) and (23).

Fig. 8 shows the scheme of the MCM demodulator implemented in Matlab, which consist in using an I/Q demodulator per carrier [11]. Each branch has a band-pass filter that passes the frequency components around the carrier frequency. After that, both the in-phase and the quadrature components of the carrier are obtained. Finally, the amplitude and the phase of the carrier are calculated. It is important to note that the demodulator can be simplified for certain MCM

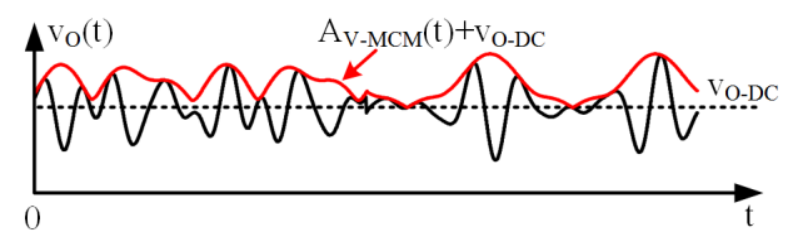

(a)

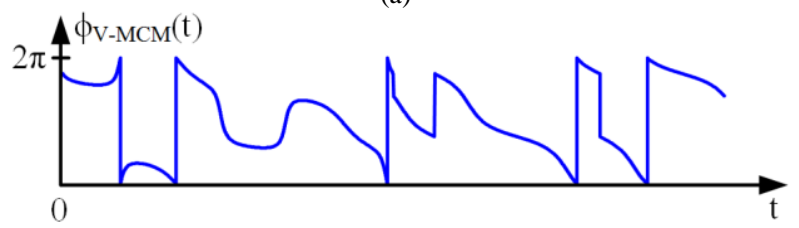

(b)

Fig. 7. References that must be tracked in order to reproduce a MCM scheme with the RM: (a) $A_{V}(t)$ must track the envelope of the communication signal. (b) $\phi_{\mathrm{V}}(\mathrm{t})$ must track the instantaneous phase of the communication signal.
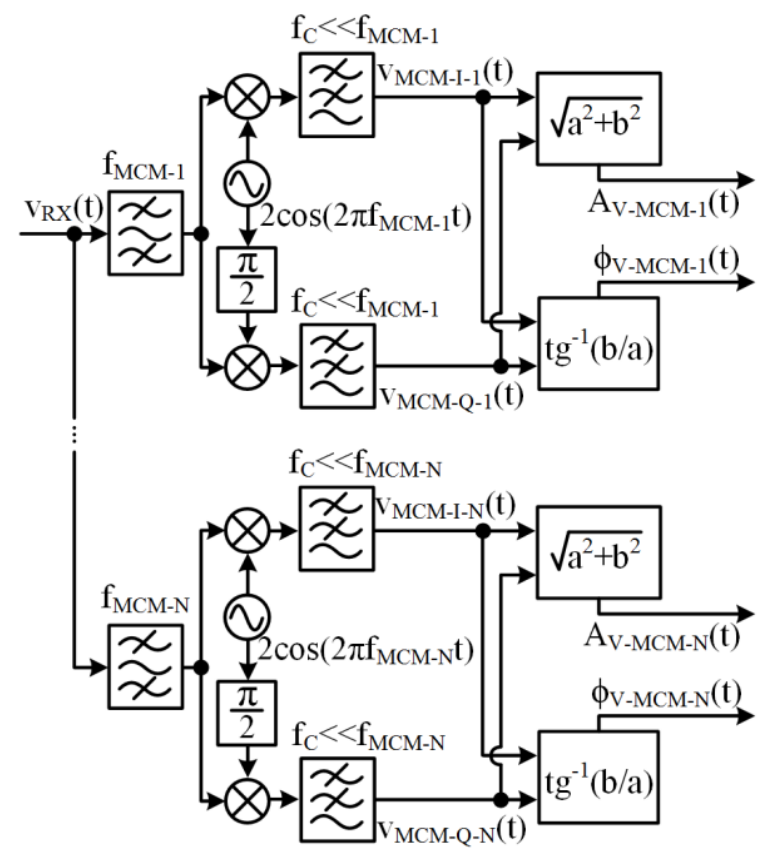

Fig. 8. Blocks diagram of the demodulator.

schemes, such as Orthogonal Frequency Division Multiplexing (OFDM), which has some characteristics that allow us to use a demodulator architecture based on the Fast Fourier Transform (FFT) [11], [14].

\section{CONTROL SYSTEM}

Fig. 1 shows the power stage and the main blocks of the control system used to apply the RM. The inputs are the voltage envelope reference $\left(A_{V-R e f}(t)\right)$ and the instantaneous phase voltage reference $\left(\phi_{V-R e f}(t)\right)$ that must be tracked by $A_{v}(t)$ and $\phi_{\mathrm{V}}(\mathrm{t})$, respectively; the measurement of the current that flows through the HB-LEDs $\left(\mathrm{i}_{\mathrm{O}}(\mathrm{t})\right)$ and the DC current reference (io-DC-Ref), which in turns determines the lighting level. The outputs of the control system are the pulse voltage waveforms that feed the gates of the MOSFETs: $v_{\mathrm{G} 1-1}(\mathrm{t}), \mathrm{v}_{\mathrm{G} 1-2}(\mathrm{t}), \mathrm{v}_{\mathrm{G} 2-1}(\mathrm{t})$ and $\mathrm{v}_{\mathrm{G} 2-2}(\mathrm{t})$ for $\mathrm{Q}_{1-1}, \mathrm{Q}_{1-2}, \mathrm{Q}_{2-1}$ and $\mathrm{Q}_{2-2}$, respectively. A general description of the main blocks can be found below.

\section{A. $d(t)$ Calculator}

This block calculates the duty cycle value required for properly biasing the HB LEDs (see Fig. 9). io(t) is sensed and 


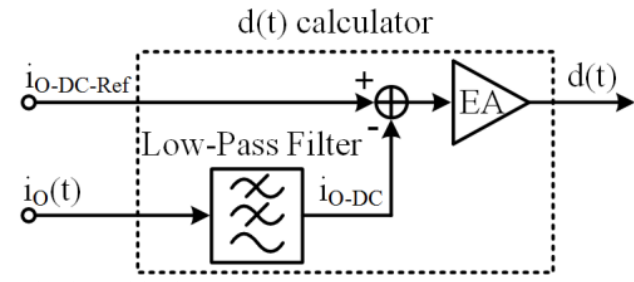

Fig. 9. $d(t)$ calculator block.

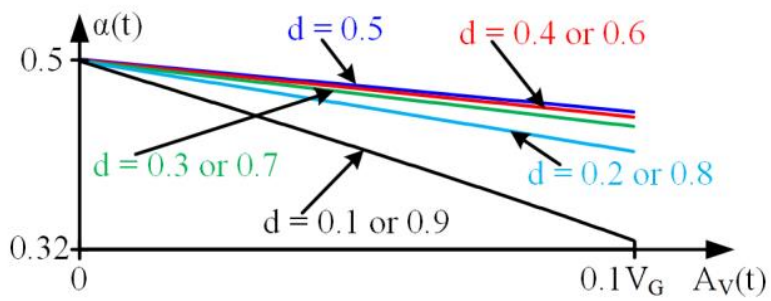

Fig.10. $\alpha(t)$ versus $A_{V}(t)$ when $A_{V}(t) \ll<V_{G}$.

filtered to measure the DC component of the output current (io-DC). Since this value determines the lighting level, io-DC-Ref is compared to io-DC. After that, the Error Amplifier (EA) provides the $\mathrm{d}(\mathrm{t})$ value that ensures the desired lighting level.

\section{B. $\alpha(t)$ Calculator}

This blocks calculates $\alpha(t)$ to provide the desired $A_{v}(t)$. The calculation that must be carried out can be obtained by solving (24), which is not straightforward because the expression is quite complex and it depends not only on $A_{V-R e f}(t)$, but also on the current $d(t)$ value. As a consequence, both $A_{v-R e f}(t)$ and $d(t)$ must feed the $\alpha(t)$ calculator block (see Fig. 1). Fortunately, (24) can be simplified since, in practice, $A_{V}(t)$ is much smaller than $\mathrm{V}_{\mathrm{G}}$. This is because of the relationship between the light intensity emitted by an HB-LED, the current that flows through it and the applied voltage: once the HB-LED is properly biased, small voltage changes lead to both big current changes and big light intensity changes [16]. As Fig. 10 shows, the relationship between $\alpha(\mathrm{t})$ and $\mathrm{Av}_{v}(\mathrm{t})$ described in (24) is almost linear when $\mathrm{A}_{\mathrm{V}}(\mathrm{t}) \ll<\mathrm{V}_{\mathrm{G}}$ and, consequently, the following approximation is quite accurate:

$$
\alpha(t) \cong \alpha_{O}-m_{O}(d(t)) A_{V-R e f}(t)
$$

Note that $\alpha_{\mathrm{O}}$ is the $\alpha(\mathrm{t})$ value when $\mathrm{A}_{\mathrm{V}}(\mathrm{t})$ is $0 \mathrm{~V}$, and $\mathrm{m}_{\mathrm{O}}(\mathrm{d}(\mathrm{t}))$ is the derivate of $\alpha(t)$ with respect to $A_{v}(t)$ and evaluated in $\mathrm{A}_{\mathrm{V}}(\mathrm{t})=0 \mathrm{~V}$ :

$$
\begin{gathered}
\alpha_{O}=0.5 \\
m_{O}(d(t))=\frac{1}{2 V_{G} \sin (d(t) \cdot \pi)} .
\end{gathered}
$$

Since $\mathrm{m}_{\mathrm{O}}(\mathrm{d}(\mathrm{t}))$ depends on $\mathrm{d}(\mathrm{t})$ and the expression is not trivial, it is calculated by means of a look-up table.

\section{C. $\beta(t)$ Calculator}

Differently from the $\alpha(\mathrm{t})$ calculation, calculating $\beta(\mathrm{t})$ is straightforward following (25).

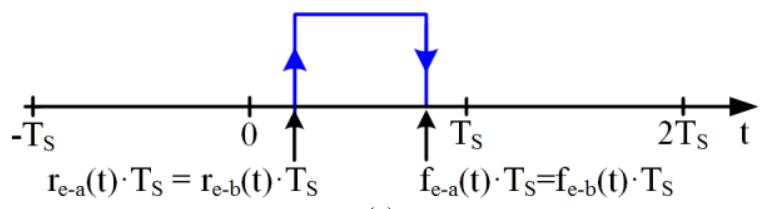

(a)

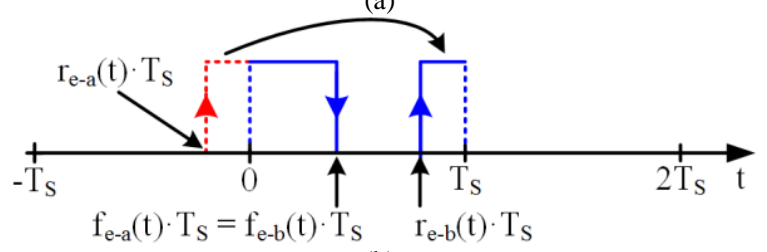

(b)

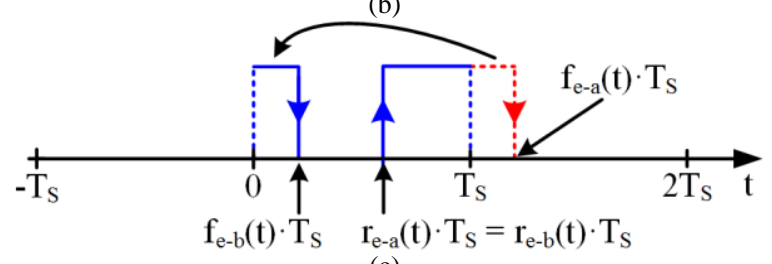

(c)

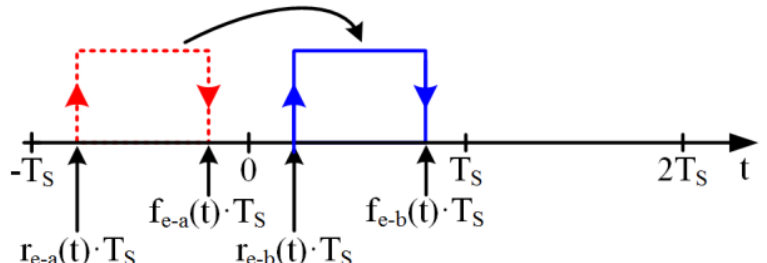

$r_{e-a}(t) \cdot T_{S} \quad r_{e-b}(t) \cdot T_{S}$

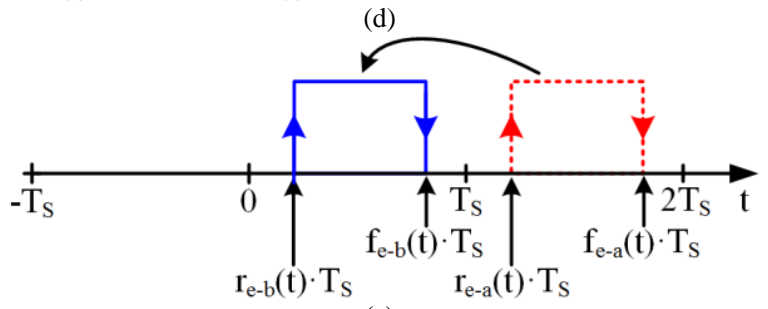

(e)

Fig. 11. Situations that could appear according to the possible values of the provisional rising and falling edges positions: (a) Situation 1. (b) Situation 2. (c) Situation 3. (d) Situation 4. (e) Situation 5.

\section{Provisional Edges Positions Calculator}

Once $d(t), \alpha(t)$ and $\beta(t)$ are calculated, the generation of the pulses can be addressed. Both $\mathrm{v}_{\mathrm{S}-1}(\mathrm{t})$ and $\mathrm{v}_{\mathrm{s}-2}(\mathrm{t})$ are proportional to the gate signals that feed $\mathrm{Q}_{1-1}$ and $\mathrm{Q}_{2-1}$. Obviously, the gate signals that feed $\mathrm{Q}_{1-2}$ and $\mathrm{Q}_{2-2}$ are the complementary ones. Therefore, and as will be shown below, the remaining part of the control system is focused on generating the gate signals that feed $\mathrm{Q}_{1-1}$ and $\mathrm{Q}_{2-1}$. As Fig. 1 shows, the last stage of the control system is the generation of the complementary gate signals that feed $\mathrm{Q}_{1-2}$ and $\mathrm{Q}_{2-2}$.

The first step is to calculate the provisional rising and falling edges positions of the pulses. The reason that explains why they are provisional values is detailed in Section IV.E. The provisional edges positions can be calculated as follows (Fig. 11(a) may help to understand the reasoning):

$$
\begin{aligned}
& r_{e-a 1}(t)=\beta(t)-\frac{\alpha(t)}{2}-\frac{d(t)}{2} \\
& f_{e-a 1}(t)=\beta(t)-\frac{\alpha(t)}{2}+\frac{d(t)}{2} \\
& r_{e-a 2}(t)=\beta(t)+\frac{\alpha(t)}{2}-\frac{d(t)}{2}
\end{aligned}
$$




$$
f_{e-a 2}(t)=\beta(t)+\frac{\alpha(t)}{2}+\frac{d(t)}{2},
$$

where $\mathrm{r}_{\mathrm{e}-\mathrm{a} 1}(\mathrm{t}), \mathrm{f}_{\mathrm{e}-\mathrm{al}}(\mathrm{t}), \mathrm{r}_{\mathrm{e}-\mathrm{a} 2}(\mathrm{t})$ and $\mathrm{f}_{\mathrm{e}-\mathrm{a} 2}(\mathrm{t})$ are the provisional rising edge position of phase 1 , the provisional falling edge position of phase 1, the provisional rising edge position of phase 2 and the provisional falling edge position of phase 2, respectively.

\section{E. Definitive Edges Positions Calculator}

The aforementioned rising and falling edges positions are provisional values because they are only valid if the pulse that must be generated does not exceed the limits of its switching period. Note that if a provisional edge position is lower than 0 or higher than 1, it means that the pulse exceeds its switching period. Considering the maximum and minimum values of $\alpha(t)$, $\beta(\mathrm{t})$ and $\mathrm{d}(\mathrm{t})$, there are five possible situations:

Situation 1: $r_{e-a}(t)>0$ and $f_{e-a}(t)<1$. The pulse does not exceed its switching period (see Fig. 11(a)). In this situation, the definitive rising and falling edges positions $\left(\mathrm{r}_{\mathrm{e}-\mathrm{b}}(\mathrm{t})\right.$ and $\mathrm{f}_{\mathrm{e}-\mathrm{b}}(\mathrm{t})$ ) are equal to the provisional ones:

$$
\begin{aligned}
& r_{e-b}(t)=r_{e-a}(t), \\
& f_{e-b}(t)=f_{e-a}(t) .
\end{aligned}
$$

Situation 2: $r_{e-a}(t)<0$ and $f_{e-a}(t)<1$. The pulse exceeds its switching period and a part of it tries to invade the previous one (see Fig. 11(b)). In this situation, the part of the pulse that tries to appear in the previous switching period must be moved to the end of the correct one:

$$
\begin{gathered}
r_{e-b}(t)=r_{e-a}(t)+1, \\
f_{e-b}(t)=f_{e-a}(t) .
\end{gathered}
$$

Situation 3: $r_{e-a}(t)<1$ and $f_{e-a}(t)>1$. The pulse exceeds its switching period and a part of it tries to invade the next one (see Fig. 11(c)). In this situation, the part of the pulse that tries to appear in the next switching period must be moved to the beginning of the correct one:

$$
\begin{gathered}
r_{e-b}(t)=r_{e-a}(t), \\
f_{e-b}(t)=f_{e-a}(t)-1 .
\end{gathered}
$$

Situation 4: $r_{e-a}(t)<0$ and $f_{e-a}(t)<0$. The pulse exceeds its switching period and tries to invade completely the previous one (see Fig. 11(d)). In this situation, the pulse must be moved to the correct switching period:

$$
\begin{aligned}
& r_{e-b}(t)=r_{e-a}(t)+1, \\
& f_{e-b}(t)=f_{e-a}(t)+1 .
\end{aligned}
$$

Situation 5: $r_{e-a}(t)>1$ and $f_{e-a}(t)>1$. The pulse exceeds its switching period and tries to invade completely the next one (see Fig. 11(e)). In this situation, the pulse must be moved to the correct switching period:

$$
\begin{aligned}
& r_{e-b}(t)=r_{e-a}(t)-1 \\
& f_{e-b}(t)=f_{e-a}(t)-1
\end{aligned}
$$

\section{F. PWPPM blocks}

The PWPPM blocks are responsible for generating the gate signals of $\mathrm{Q}_{1-1}$ or $\mathrm{Q}_{2-1}$ (i.e., $\mathrm{v}_{\mathrm{G} 1-1}(\mathrm{t})$ or $\mathrm{v}_{\mathrm{G} 2-1}(\mathrm{t})$ ) by knowing their definite rising and falling edges positions. As in the case of the PWM, the pulse generation is performed by making a comparison with a sawtooth signal $\left(\mathrm{s}_{\mathrm{w}}(\mathrm{t})\right)$ whose frequency is $\mathrm{f}_{\mathrm{S}}$ and whose maximum and minimum values are 1 and 0 , respectively. However, in the case of the PWPPM, $s_{w}(t)$ is compared to two references: the definitive rising (i.e., $r_{e-b}(t)$ ) and falling edges positions (i.e., $\mathrm{f}_{\mathrm{e}-\mathrm{b}}(\mathrm{t})$ ). In addition, the output depends on the aforementioned situations. When the situation is 1,4 or 5 (see Fig. 12(a)), $\mathrm{f}_{\mathrm{e}-\mathrm{b}}(\mathrm{t})$ is higher than $\mathrm{r}_{\mathrm{e}-\mathrm{b}}(\mathrm{t})$ and the output is (note that it is a logical equation):

$$
\begin{aligned}
& v_{G i-1}(t)= \\
& \quad\left(s_{w}(t)>r_{e-b}(t)\right) A N D\left(s_{w}(t)<f_{e-b}(t)\right) .
\end{aligned}
$$

On the other hand, when the situation is 2 or 3 (see Fig. $12(b)), f_{e-b}(t)$ is lower than $r_{e-b}(t)$ and the output is:

$$
\begin{aligned}
& v_{G i-1}(t)= \\
& \left(s_{w}(t)>r_{e-b}(t)\right) \text { OR }\left(s_{w}(t)<f_{e-b}(t)\right) .
\end{aligned}
$$

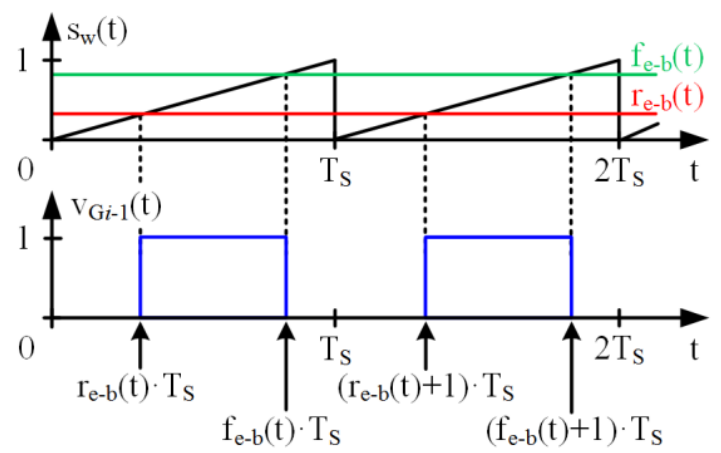

(a)

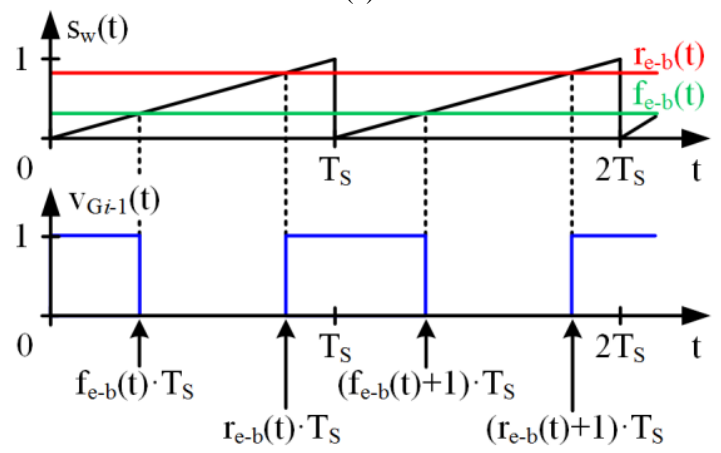

(b)

Fig. 12. Output of a PWPPM block depending on the situation: (a) Situation 1, 4 or 5. (b) Situation 2 or 3. 


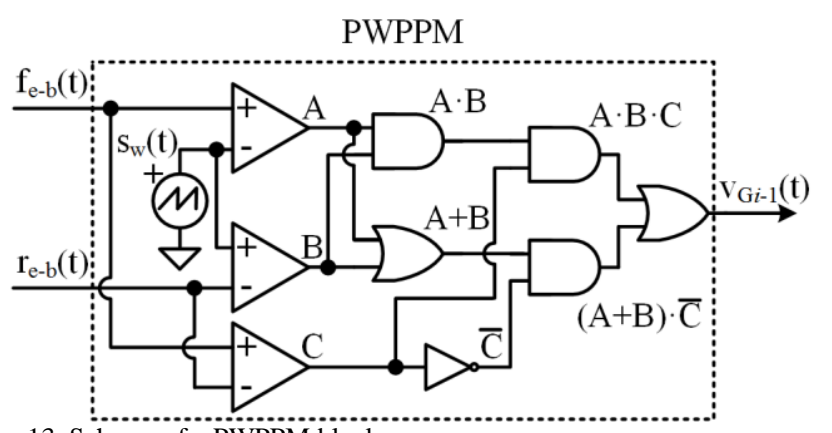

Fig. 13. Scheme of a PWPPM block.

The PWPPM blocks can be implemented by defining the following logical variables:

$$
\begin{gathered}
A=s_{w}(t)<f_{e-b}(t), \\
B=s_{w}(t)>r_{e-b}(t), \\
C=f_{e-b}(t)>r_{e-b}(t) .
\end{gathered}
$$

Considering (43)-(44), $\mathrm{v}_{\mathrm{Gi} i-1}(\mathrm{t})$ can be calculated as follows (see Fig. 13):

$$
v_{G i-1}(t)=(A \cdot B \cdot C)+(A+B) \cdot \bar{C} .
$$

\section{EXPERIMENTAL RESULTS}

A two-phase synchronous buck converter with $10^{\text {th }}$ order Butterworth filter was built in order to validate the proposed HB-LED driver for VLC (see Fig. 14(a)). The cut-off frequency of the filter is $650 \mathrm{kHz}\left(\mathrm{L}_{1-1}=\mathrm{L}_{1-2}=4.26 \mu \mathrm{H}, \mathrm{C}_{2}=82 \mathrm{nF}, \mathrm{L}_{3}=2.47\right.$ $\mu \mathrm{H}, \mathrm{C}_{4}=74 \mathrm{nF}, \mathrm{L}_{5}=2.05 \mu \mathrm{H}, \mathrm{C}_{6}=57 \mathrm{nF}, \mathrm{L}_{7}=1.42 \mu \mathrm{H}, \mathrm{C}_{8}=34 \mathrm{nF}$, $\mathrm{L}_{9}=633 \mathrm{nH}$ and $\mathrm{C}_{10}=7 \mathrm{nF}$ ). The SMPC supplies a string of five HB-LEDs (W42180 Seoul Semiconductor). The switching frequency is $500 \mathrm{kHz}$, the input voltage is $30 \mathrm{~V}$ and the maximum power is around $10 \mathrm{~W}$. SSM3K361R MOSFETs are used driven by EL7156 ICs. The control system described in section IV is implemented in a Field Programmable Gate Array (FPGA): Spartan-6. Fig. 14(b) shows that the power efficiency of the proposed SMPC ranges between 95\% and 96.5\% depending on the dimming level. It must be pointed out that the efficiency is quite independent of $\mathrm{Av}_{\mathrm{v}}(\mathrm{t})$.

\section{A. Main Experimental Waveforms}

Fig. 15 shows the main experimental waveforms of the SMPC in steady-state conditions (i.e., constant $A_{v}(t)$ and $\phi_{V}(t)$ ) in two situations: $A_{V}(t)$ is much higher in Fig. 15(a) than in Fig. 15(b). As can be seen, the cosine waveform is reproduced with high accuracy in both cases. As indicated in Section IV.B, the high output voltage accuracy demanded by the VLC application is translated into high $\alpha(\mathrm{t})$ accuracy: the control system uses $\alpha(\mathrm{t})$ values that are very close to 0.5 because $A_{v}(t)<<V_{G}$. Note the small difference between the phase-shift in Fig. 15(a) and that of Fig. 15(b); and also that both values are close to $\pi$ radians.

In order to evaluate the capability to reproduce a MCM scheme, a signal that is made up of six carriers is reproduced. Each carrier keeps its amplitude, phase and frequency constant

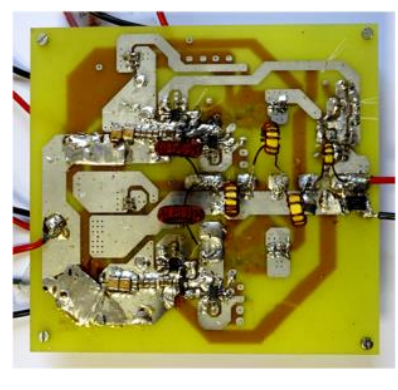

(a)

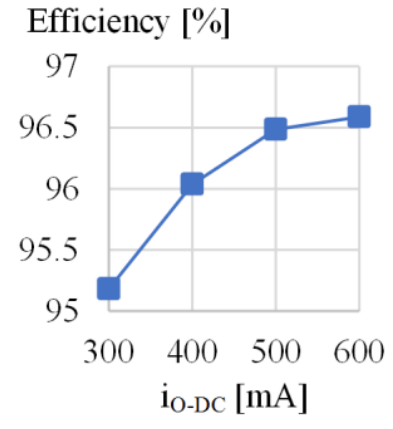

(b)
Fig. 14. MCM transmitter based on the RM: (a) Prototype. (b) Efficiency versus dimming level.

TABLE I. MAIN PARAMETERS OF THE MCM SCHEME.

\begin{tabular}{ccccccc}
\hline \hline & $\mathbf{c}_{\mathbf{1}}$ & $\mathbf{c}_{\mathbf{2}}$ & $\mathbf{c}_{\mathbf{3}}$ & $\mathbf{c}_{\mathbf{4}}$ & $\mathbf{c}_{5}$ & $\mathbf{c}_{\mathbf{6}}$ \\
\hline $\begin{array}{c}\text { Frequency } \\
\text { (kHz) }\end{array}$ & 475 & 485 & 495 & 505 & 515 & 525 \\
\hline Amplitude & $1 \cdot \mathrm{A}$ & $4 \cdot \mathrm{A}$ & $2 \cdot \mathrm{A}$ & $1 \cdot \mathrm{A}$ & $3 \cdot \mathrm{A}$ & $2 \cdot \mathrm{A}$ \\
\hline Phase (rad) & $\pi / 2$ & 0 & $\pi$ & $\pi / 2$ & $3 \cdot \pi / 2$ & 0 \\
\hline
\end{tabular}
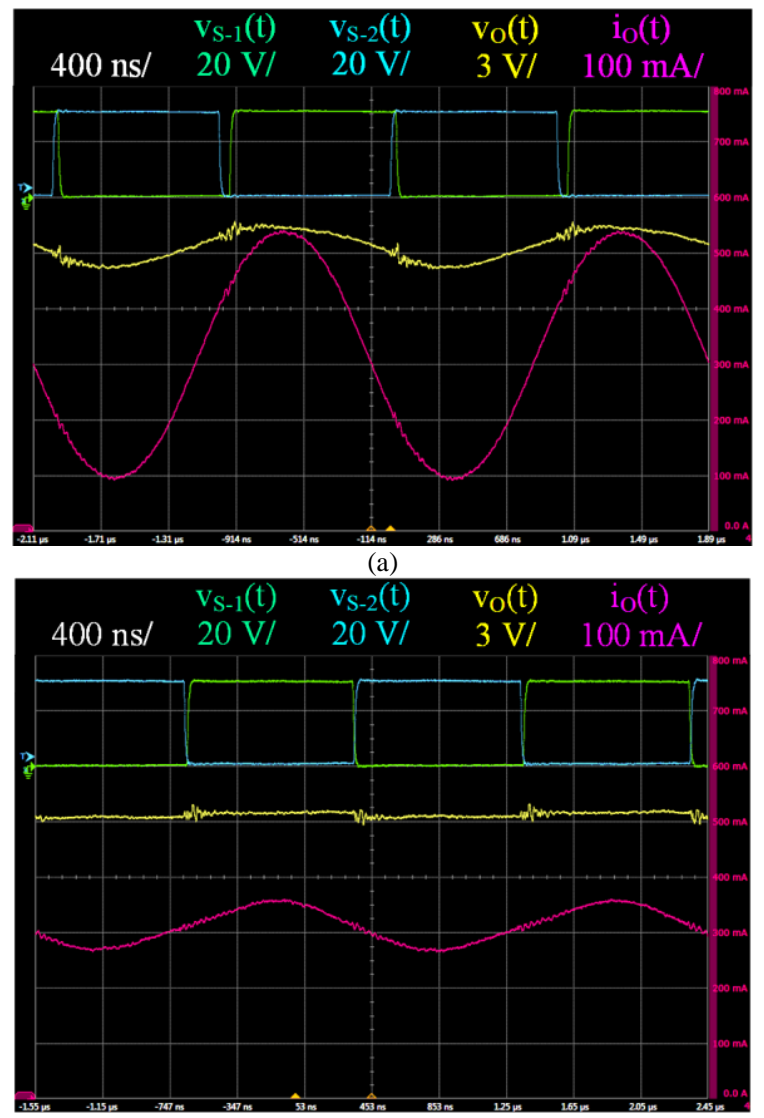

(b)

Fig. 15. Main experimental waveforms of the HB-LED driver for VLC in steady-state conditions (i.e., constant $A_{V}(t)$ and $\phi_{V}(t)$ ) for two $A_{v}(t)$ values: (a) High $A_{V}(t)$ value. (b) Low $A_{V}(t)$ value.

over time. Table I shows the characteristics of each carrier $\left(\mathrm{c}_{1}\right.$, $\left.\mathrm{c}_{2}, \ldots, \mathrm{c}_{6}\right)$. Note that the amplitude modulation is normalized: the parameter A depends on the communication signal power that is used for performing the transmission. The commercial receiver PDA10A-EC provides a voltage waveform $\left(\mathrm{v}_{\mathrm{RX}}(\mathrm{t})\right)$ that is proportional to the received light intensity. Fig. 16(a) shows the main waveforms of the VLC setup in the time domain 


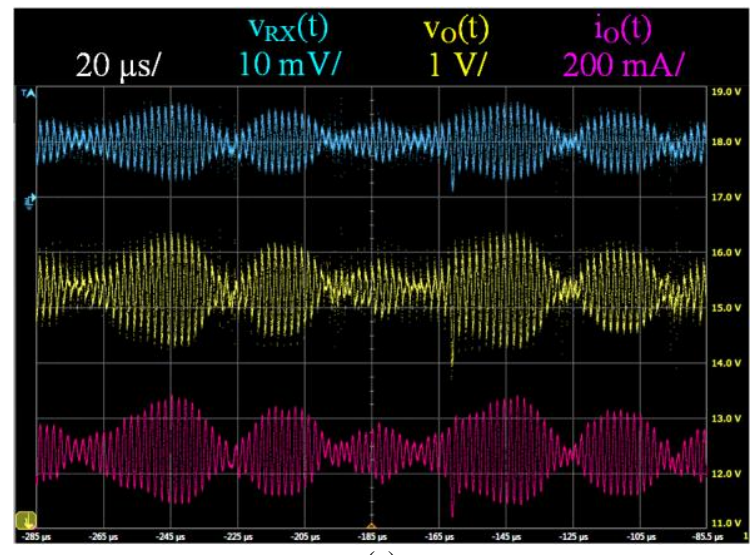

(a)

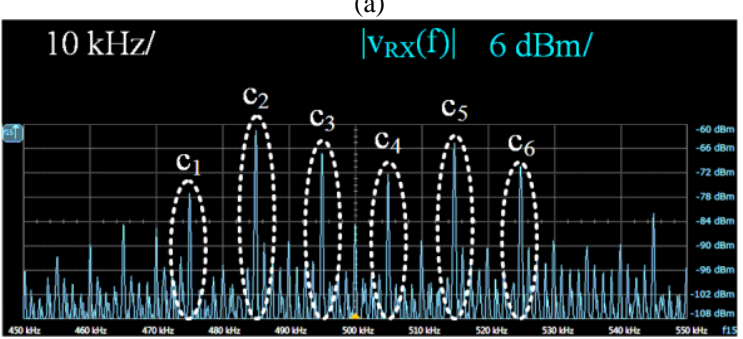

(b)

Fig. 16. Main experimental waveforms of the VLC link (distance: $40 \mathrm{~cm}$ ): (a) Time domain. (b) Frequency domain.

when the aforementioned MCM scheme is reproduced. Fig. 16(b) shows the magnitude of $\mathrm{V}_{\mathrm{RX}}(\mathrm{t})$ in the frequency domain. As in any transmission system, the received signal is made up of the information (i.e., the modulated carriers) and noise that damages the communication. At this point, it is very important to study the robustness of the communication link by evaluating the error of the waveforms and by analyzing how that error damages the communication capability.

\section{B. Analysis of the Communication Link Error}

Since the contribution of the paper is the proposed HB-LED driver and its control system, evaluating its accuracy is essential. This point can be studied in two steps. First, the accuracy for reproducing the desired $\mathrm{v}_{\mathrm{O}}(\mathrm{t})$ is evaluated, and second, the conversion between $v_{O}(t)$ and $s(t)$ is analyzed. Fig. 17(a) shows the envelope of the theoretical signal ( $\left.\mathrm{A}_{\text {Th-Nor }}(\mathrm{t})\right)$ obtained with Matlab, and the envelope $\left(A_{v-N o r}(t)\right)$ of the $A C$ component of $\mathrm{v}_{\mathrm{O}}(\mathrm{t})\left(\mathrm{v}_{\mathrm{O}-\mathrm{AC}}(\mathrm{t})\right)$. In order to enable a comparison, both waveforms are scaled to have a communication signal with energy equal to $1 \mathrm{~J}$. Both the instantaneous phase of the theoretical signal $\left(\phi_{T h}(t)\right)$ and $\phi_{\mathrm{V}}(\mathrm{t})$ can be seen in Fig. 17(b). The next step is to evaluate the conversion between $v_{0}(t)$ and $\mathrm{s}(\mathrm{t})$ that is performed by the HB-LEDs. Fig. 18 shows the comparison between the envelopes and the instantaneous phases of both $\mathrm{v}_{\mathrm{O}-\mathrm{AC}}(\mathrm{t})$ and $\mathrm{V}_{\mathrm{RX}-\mathrm{AC}}(\mathrm{t})$. As in the previous case, the envelopes are normalized in order to have a communication signal with energy equal to $1 \mathrm{~J}$. The relationship between $\mathrm{v}_{\mathrm{O}-\mathrm{AC}}(\mathrm{t})$ and $\mathrm{s}_{\mathrm{AC}}(\mathrm{t})$ is quite linear and, consequently, the conversion between voltage and light intensity does not add a remarkable error. It is important to note that this measurement of $\mathrm{s}(\mathrm{t})$ is performed when the receiver is close to the transmitter $(20 \mathrm{~cm})$ in order to minimize the impact of the link distance $\left(\mathrm{L}_{\mathrm{D}}\right)$, which will be considered below. As a conclusion, the error of tracking the voltage references (i.e., $A_{V-\text { Ref }}(t)$ and $\left.\phi_{V-\text { Ref }}(t)\right)$ is the main error source of the proposed HB-LED driver.

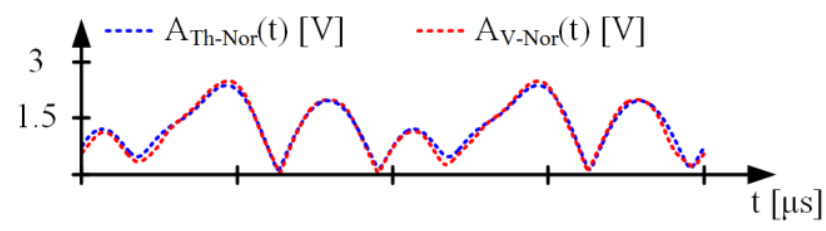

(a)

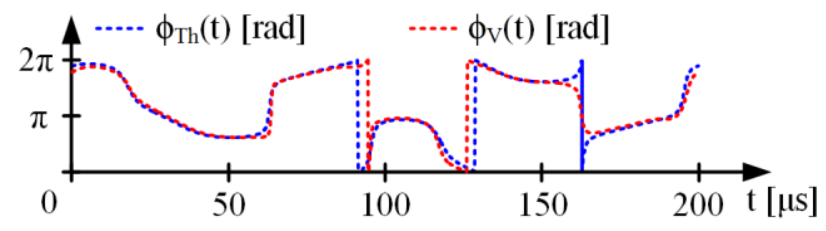

(b)

Fig. 17. First step of the accuracy evaluation of the proposed HB-LED driver for VLC: (a) Comparison between the theoretical envelope and the envelope of $\mathrm{V}_{\mathrm{O}-\mathrm{AC}}(\mathrm{t})$ when they are scaled to have a communication signal with energy equal to $1 \mathrm{~J}$. (b) Comparison between the theoretical instantaneous phase and the instantaneous phase of $\mathrm{v}_{\mathrm{O}-\mathrm{AC}}(\mathrm{t})$.

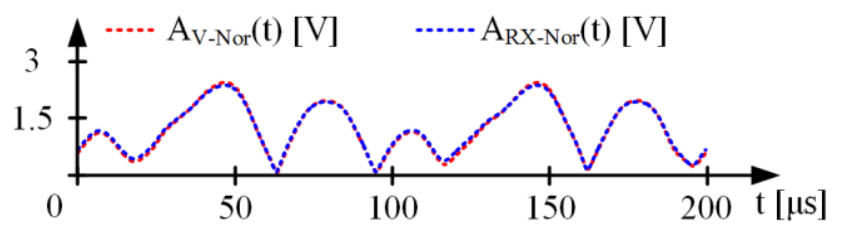

(a)

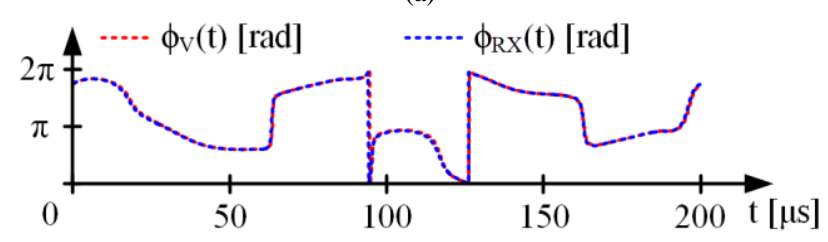

(b)

Fig. 18. Second step of the accuracy evaluation of the proposed HB-LED driver for VLC: (a) Comparison between the envelope of $\mathrm{v}_{\mathrm{O}-\mathrm{AC}}(\mathrm{t})$ and the envelope of $\mathrm{v}_{\mathrm{RX}-\mathrm{AC}}(\mathrm{t})$ (both waveforms are normalized in order to have a signal with energy equal to $1 \mathrm{~J}$. (b) Comparison between the instantaneous phase of $\mathrm{v}_{\mathrm{O}-\mathrm{AC}}(\mathrm{t})$ and the instantaneous phase of $v_{R X-A C}(t)$. Note that $L_{D}$ is $20 \mathrm{~cm}$.

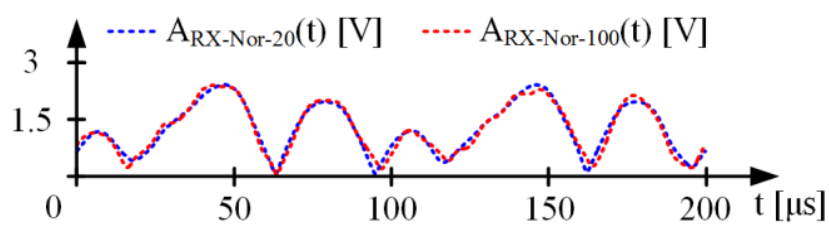

(a)

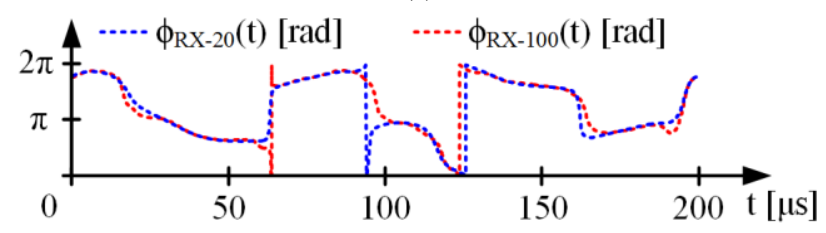

(b)

Fig. 19. Deterioration of the signal when the link distance rises from $20 \mathrm{~cm}$ to $100 \mathrm{~cm}$ : (a) Envelope of $\mathrm{v}_{\mathrm{RX}-\mathrm{AC}}(\mathrm{t})$. (b) Instantaneous phase of $\mathrm{v}_{\mathrm{RX}-\mathrm{AC}}(\mathrm{t})$.

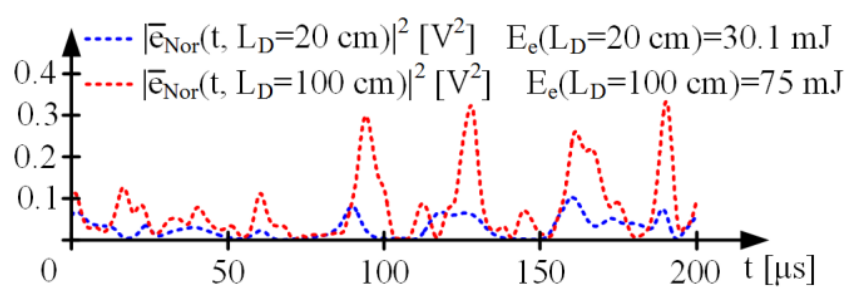

Fig. 20. Example of the error calculation when $L_{D}$ is $20 \mathrm{~cm}$ and $100 \mathrm{~cm}$. 
As in any communication system, the increase of $L_{D}$ leads to an error increase. As an example, Fig. 19 shows how the received envelope $\left(A_{R X}(t)\right)$ and the received instantaneous phase $\left(\phi_{R X}(t)\right)$ are deteriorated when $L_{D}$ rises from $20 \mathrm{~cm}$ to 100 $\mathrm{cm}$.

In order to evaluate the error taking into account both the amplitude and the phase error, the following normalized error vector is used:

$$
\begin{aligned}
& \bar{e}_{N o r}\left(t, L_{D}\right)= \\
& \quad A_{T h}(t) e^{j \cdot \phi_{T h}(t)}-A_{R X-N o r}\left(t, L_{D}\right) e^{j \cdot \phi_{R X}\left(t, L_{D}\right)} .
\end{aligned}
$$

At this point, the energy of the normalized error vector allows us to evaluate the deterioration of the communication signal:

$$
E_{e}\left(L_{D}\right)=\frac{1}{T} \int_{t=0}^{T}\left|\bar{e}_{N o r}\left(t, L_{D}\right)\right|^{2} d t
$$

where $\mathrm{T}$ is the period of the signal ( $200 \mu$ s in our case). Fig. 20 exemplifies the calculation of $\mathrm{E}_{\mathrm{e}}\left(\mathrm{L}_{\mathrm{D}}\right)$ when $\mathrm{L}_{\mathrm{D}}$ is $20 \mathrm{~cm}$ and 100 cm. Moreover, Fig. 21 shows how $\mathrm{E}_{\mathrm{e}}\left(\mathrm{L}_{\mathrm{D}}\right)$ rises with $\mathrm{L}_{\mathrm{D}}$. $\mathrm{E}_{\mathrm{e}}\left(\mathrm{L}_{\mathrm{D}}\right)$ allows us to evaluate the error in a general way because its definition is valid for any kind of communication signal. However, it is important to analyze how that error damages the communication capability. In the particular case of a MCM scheme, that analysis is translated into the study of how the error affects the different carriers. In order to address that point, $\mathrm{V}_{\mathrm{RX}}(\mathrm{t})$ is demodulated and the amplitude and phase of each carrier is evaluated. Fig. 22 shows the amplitude and the phase of the received modulated carriers for different link distances (i.e., from $20 \mathrm{~cm}$ to $100 \mathrm{~cm}$ ). Note that the results are given in polar form with the amplitude normalized to have a communication signal with energy equal to $1 \mathrm{~J}$. As can be seen, the error causes that the amplitude and the phase of the received carriers do not match perfectly with the theoretical ones. Basically, it determines how many symbols can be distinguished by the receiver: the lower the error, the closer the symbols can be placed and, consequently, a higher number of symbols can be considered. In this case, a normalized error vector can be calculated for each carrier and for each $L_{D}$ :

$$
\begin{gathered}
\bar{e}_{k-N o r}\left(t, L_{D}\right)=A_{k-T h}(t) e^{j \cdot \phi_{k-T h}(t)}- \\
A_{k-R X-N o r}\left(t, L_{D}\right) e^{j \cdot \phi_{k-R X}\left(t, L_{D}\right)}
\end{gathered}
$$

where $\mathrm{A}_{\mathrm{k}-\mathrm{Th}}(\mathrm{t})$ is the theoretical amplitude of the $k^{\text {th }}$ carrier when the communication signal is normalized to have energy equal to $1 \mathrm{~J}, \phi_{\mathrm{k}-\mathrm{Th}}(\mathrm{t})$ is the phase of the $k^{\text {th }}$ carrier, $\mathrm{A}_{\mathrm{k}-\mathrm{RX} \text {-Nor }}\left(\mathrm{t}, \mathrm{L}_{\mathrm{D}}\right)$ is the amplitude of the received $k^{\text {th }}$ carrier when the communication signal is normalized to have energy equal to $1 \mathrm{~J}$ and $\phi_{\mathrm{k}-\mathrm{RX}}\left(\mathrm{t}, \mathrm{L}_{\mathrm{D}}\right)$ is the phase of the received $k^{\text {th }}$ carrier. Then, the energy of the normalized error vector can be evaluated as follows:

$$
E_{e-M C M-k}\left(L_{D}\right)=\frac{1}{T} \int_{t=0}^{T}\left|\bar{e}_{k-N o r}\left(t, L_{D}\right)\right|^{2} d t .
$$

Finally, the average energy of the normalized error vector per carrier can be calculated as follows (see Fig. 23):

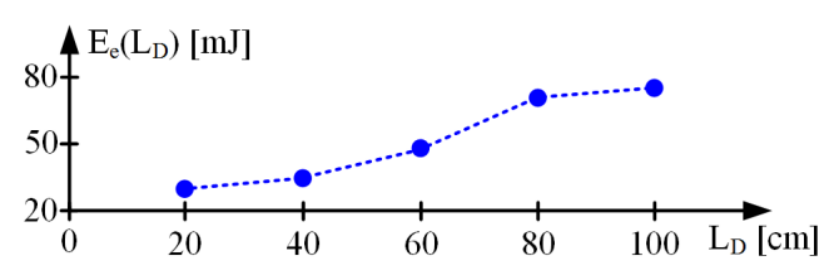

Fig. 21. Increase of $E_{e}\left(L_{D}\right)$ with $L_{D}$. Note that the error definition considers signals with energy equal to $1 \mathrm{~J}$.

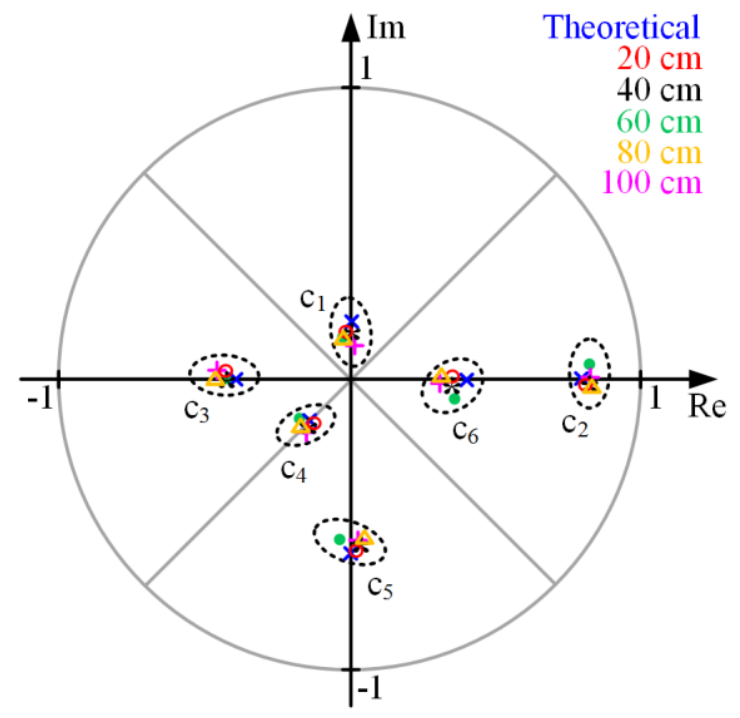

Fig. 22. Polar representation of the demodulated carriers normalized to have a signal with energy equal to $1 \mathrm{~J}$. Note that the results of $\mathrm{c}_{4}$ are $3 \cdot \pi / 4$ phase-shifted in order to avoid the overlap with the results of $c_{1}$.

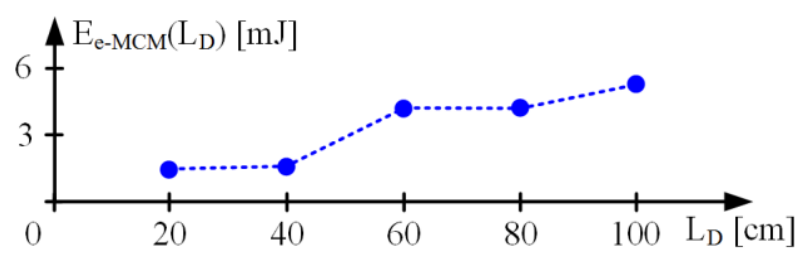

Fig. 23. Average energy of the normalized error vector per carrier versus $L_{D}$. Note that the error definition considers signals with energy equal to $1 \mathrm{~J}$.

$$
E_{e-M C M}\left(L_{D}\right)=\frac{1}{6} \sum_{k=1}^{6} E_{e-M C M-k}\left(L_{D}\right) .
$$

It can be seen that the average energy of the normalized error vector per carrier rises with $L_{D}$. In other words, the difference between the transmitted symbols and the received ones tends to rise as the receiver is moved away from the transmitter. As a consequence, the number of symbols that can be distinguished by the receiver falls with $L_{D}$.

\section{CONCLUSION}

The RM is a very interesting technique for the HB-LED drivers of VLC transmitters. It achieves high power efficiency because of the use of a SMPC, thus avoiding the use of power inefficient LPAs. In comparison to the approaches based on the use of PWM-SMPCs, the power stage is simpler and the required $f_{S}$ is much lower, which facilitates the practical implementation and leads to lower switching losses (main source of losses in this application). Moreover, the main 
drawback of the RM has been overcome in this work. The reported theoretical analysis demonstrates that the RM can be used to reproduce MCM schemes (i.e., the most recommended modulation schemes for VLC) by using a $f_{S}$ value equal to the center frequency and by modulating the amplitude and the phase of the output voltage ripple according to the envelope and the instantaneous phase.

The control system of the two-phase synchronous buck converter based on the RM is quite different from that of a conventional SMPC. It must apply the PWPPM, which is translated into controlling not only the width of the switch-node voltages, but also their position over the switching period. One of the critical points is the control of the phase-shift between the switch-node voltages, which allows us to modulate the amplitude of $\mathrm{V}_{\mathrm{O}-\mathrm{AC}}(\mathrm{t})$. Calculating the phase-shift that is required for providing the desired amplitude is not trivial because it involves complex mathematical expressions and it could lead to a very sophisticated digital hardware responsible for the control system. Fortunately, the calculation can be simplified and a linear function can be used taking into account that the required phase-shift is always close to $\pi$ radians. The generation of the pulse-width and pulse-phase modulated voltages that drive the MOSFETs is another fundamental point. Once the width and the phase of the pulse have been calculated, the rising and falling instants must be addressed. At this point, it is very important to take into account that a pulse could try to invade the previous or the next switching period. Therefore, the control system is also responsible for managing these situations.

The implemented two-phase synchronous buck converter demonstrates experimentally the theoretical analysis: a MCM scheme made up of six carriers is reproduced in a power efficient way (around 96\%).

\section{REFERENCES}

[1] Cisco Systems, "Cisco visual networking index: global mobile data traffic forecast update, 2016-2021", Feb. 2017. [Online]. Available: http://www.cisco.com/c/en/us/solutions/collateral/serviceprovider/visual-networking-index-vni/mobile-white-paper-c11520862.htmlasdsad

[2] L. Atzori, A. Iera, and G. Morabito, "The internet of things: a survey," Comput. Netw., vol. 54, no. 15, pp. 2787-2805, 2010.

[3] J. Gubbi, R. Buyya, S. Marusic, and M. Palaniswami, "Internet of Things (IoT): a vision, architectural elements, and future directions," Future Generat. Comput. Syst., vol. 29, no. 7, pp. 1645-1660, Sep. 2013. [Online]. Available: http://dx.doi.org/10.1016/j.future.2013.01.010

[4] S. Dimitrov, and H. Haas, Principles of LED light communications. Towards networked Li-Fi. Cambridge University Press, 2015.

[5] H. Elgala, R. Mesleh, and H. Haas, "Indoor optical wireless communication: potential and state-of-the-art," IEEE Commun. Mag., vol. 49, no. 9, pp. 56-62, Sep. 2011.

[6] H. Haas, C. Chen, and D. O'Brien, "A guide to wireless networking by light," In Progress in Quantum Electronics, vol. 55, pp. 88-111, Sep. 2017.

[7] A. Jovicic, J. Li and T. Richardson, "Visible light communication: opportunities, challenges and the path to market," in IEEE Communications Magazine, vol. 51, no. 12, pp. 26-32, December 2013.

[8] J. M. Kahn and J. R. Barry, "Wireless infrared communications," in Proceedings of the IEEE, vol. 85, no. 2, pp. 265-298, Feb 1997.

[9] J. Sebastián, D. G. Lamar, D. G. Aller, J. Rodríguez and P. F. Miaja, "On the role of power electronics in visible light communication," in IEEE Journal of Emerging and Selected Topics in Power Electronics, vol. 6, no. 3, pp. 1210-1223, Sept. 2018.

[10] J. Vučić, C. Kottke, K. Habel and K. D. Langer, "803 Mbit/s visible light WDM link based on DMT modulation of a single RGB LED luminary," Optical Fiber Communication Conference and Exposition
(OFC/NFOEC), 2011 and the National Fiber Optic Engineers Conference, Los Angeles, CA, 2011, pp. 1-3.

[11] E. McCune, Practical digital wireless signals. Cambridge University Press, 2010.

[12] Z. Ghassemlooy, L. N. Alves, S. Zvanovec, and A. Khalighi, Visible light communications: theory and applications. CRC Press, 2017.

[13] J. Armstrong and A. J. Lowery, "Power efficient optical OFDM," in Electronics Letters, vol. 42, no. 6, pp. 370-372, Mar. 2006.

[14] J. Armstrong, "OFDM for optical communications," in Journal of Lightwave Technology, vol. 27, no. 3, pp. 189-204, Feb. 2009.

[15] J. Rodríguez, D. G. Lamar, D. G. Aller, P. F. Miaja and J. Sebastián, "Efficient visible light communication transmitters based on switchingmode dc-dc converters," in Sensors, vol. 18, no. 4, 2018.

[16] J. Rodríguez, D. G. Lamar, P. F. Miaja, D. G. Aller and J. Sebastián, "Power-Efficient VLC Transmitter Based on Pulse-Width Modulated DC-DC Converters and the Split of the Power," in IEEE Transactions on Power Electronics, vol. 34, no. 2, pp. 1726-1743, Feb. 2019.

[17] J. Rodríguez, D. G. Lamar, P. F. Miaja and J. Sebastián, "Reproducing single-carrier digital modulation schemes for VLC by controlling the first switching harmonic of the DC-DC power converter output voltage ripple," in IEEE Transactions on Power Electronics, vol. 33, no. 9, pp. 7994-8010, Sept. 2018.

[18] J. Rodríguez, D. G. Lamar, D. G. Aller, P. F. Miaja and J. Sebastián, "Power-efficient VLC transmitter able to reproduce multi-carrier modulation schemes by using the output voltage ripple of the HB-LED rriver," 2018 IEEE 19th Workshop on Control and Modeling for Power Electronics (COMPEL), Padua, 2018, pp. 1-8.

[19] J. G. Proakis, Digital communications, $4^{\text {th }}$ ed. New York: McGrawHill, 2000

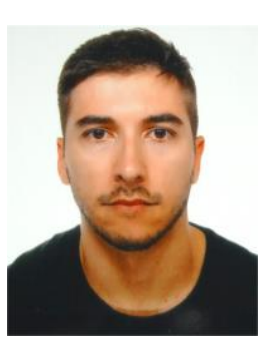

Juan Rodríguez (S'15, M'19) was born in Avilés, Spain, in 1991. He received the M.Sc. degree in telecommunication engineering and the Ph.D. in electrical engineering from the University of Oviedo, Spain, in 2014 and 2018, respectively.

Since 2015, he has been a Member of the Power Supply System Group (University of Oviedo), where he is currently working as post-doc researcher.

His research interests are focused on high-frequency DC-DC power converters, wide bandgap semiconductors and LED drivers for visible light communication.

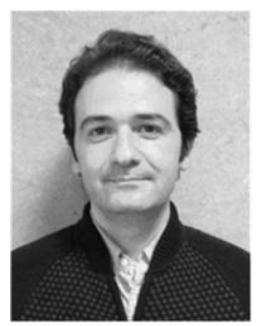

Diego G. Lamar (M'08) was born in Zaragoza, Spain, in 1974. He received the M.Sc. degree, and the Ph.D. degree in Electrical Engineering from the University of Oviedo, Spain, in 2003 and 2008, respectively.

In 2003 and 2005 he became a Research Engineer and an Assistant Professor, respectively at the University of Oviedo. Since September 2011, he has been an Associate Professor.

His research interests are focused in switching-mode power supplies, converter modelling, and power-factor-correction converters. 


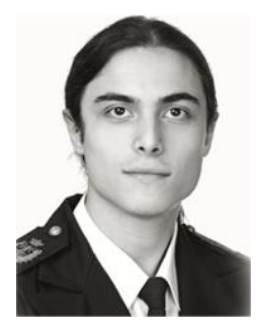

Daniel G. Aller (S'16) was born in Oviedo, Spain, in 1992. He received the M. Sc. degree in Telecommunication engineering in 2016 from the University of Oviedo, Gijon, Spain, where he is currently working towards the Ph.D. degree in electrical engineering.

His research interests include LED drivers for visible light communication, high-frequency DC-DC converters and wide bandgap semiconductors.

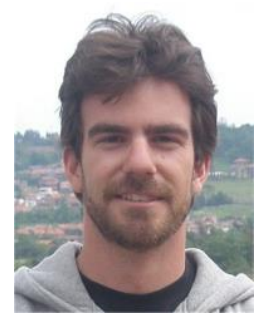

Pablo F. Miaja (S'07, M'13) was born in Oviedo, Spain, in 1984. He received the M.S. degree in telecommunication engineering from the University of Oviedo (Spain) in 2007 and in 2012 the PhD. degree from the same university. Between December 2007 and November 2014, he worked as a researcher at the Electronic Power Supply Systems Group of the University of Oviedo. Between November 2014 and May 2016, he was a Research Associate at the Power conversion Group of the University of Manchester (U.K). Between June 2016 and September 2018, he worked as an Electrical Power Conditioning Engineer at the Electrical Power Management Section at the European Space Agency. Since September 2018, he is a Lecturer at the University of Oviedo (Spain).

His research interests include $\mathrm{dc} / \mathrm{dc}$ conversion, wide band-gap power devices, digital control of switched mode power supplies and power-supply systems.

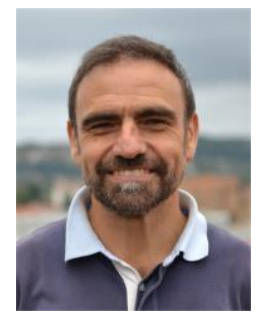

Javier Sebastián (M'87, SM'11) was born in Madrid, Spain, in 1958. He received the M.Sc. degree in electrical engineering from the Technical University of Madrid (UPM), and the Ph.D. degree in electrical engineering from the University of Oviedo, Spain, in 1981 and 1985, respectively. He was an Assistant Professor and an Associate Professor at both the UPM and the University of Oviedo. Since 1992, he has been with the University of Oviedo, where he is currently a Professor.

His research interests are switching-mode power supplies, modeling of dc-to-dc converters, low output voltage dc-to-dc converters, high power factor rectifiers, LED drivers, dc-to-dc converters for envelope tracking techniques and the use of wide band-gap semiconductors in power supplies. 